\title{
College PE Reform Based on Sunshine Sports
}

\author{
Hui Jin \\ University of Electronic Science and Technology of China, Chengdu Sichuan, 610054, China
}

Keywords: Sunshine Sports, College, College student, Education reform, Restraining factor

\begin{abstract}
In current stage, quality-oriented education has become the foundation of establishing a state. The purpose of quality-oriented education is to cultivate students' integrated development and be useful and practical talents. Sunshine Sports education reform is especially valued by the industry. It not just overall implements people-oriented scientific development thought, but also actively implements regulations of Students' Physical Health Standard. Sunshine Sports expects to regard promotion of students' physical health as the goal in a short term, deeply reform college PE education for a long term and finally achieve the purpose of nationwide fitness. Based on D College, this paper focuses on PE reform for discussion and analyzes Sunshine Sports education, restraining factors and reform countermeasures of D College.
\end{abstract}

\section{Introduction}

The education objective of Sunshine Sports is consistent with quality-based PE education. Both can intensify students' physique and achieve PE skill learning. However, Sunshine Sports owns time limit property, objective property and quantitative criteria as well as the function of reinforcing the weak link of college PE. In college PE, traditional quality-oriented PE has different emphases with Sunshine Sports, but the two have no contradiction. They can be carried out jointly to achieve mutual promotion.

\section{Sunshine Sports}

\section{Connotation of Sunshine Sports}

The implementation time of Sunshine Sports is short in Chinese colleges. For colleges, it is still a strange term. Its connotation is that students should establish such health concept that "to take exercise for $1 \mathrm{~h}$ per day can work healthily for 50 years and live happily in all one's life". Each college student should be supervised and urged to transform the idea to actual action.

\section{Objective of Sunshine Sports education}

Sunshine Sports education aims to cultivate students' one thought, two goals and three gains. One thought is that students clearly know the whole learning process and the education thought of "lifelong sports and lifelong benefit" through PE teachers' skill transference. The two goals are that students are expected to gain autonomous learning ability and the ability to independently research learning contents. In PE course, students should learn how to do physical exercise and clearly know how to improve their physical function and physique. Three gains: firstly, students should gain process and success experience, and cultivate their interest in PE through participating in sports activities. Secondly, students should pay less attention to success and failure, improve psychological quality, make friends through sports and promote their sociability and mentality in sports participation process. Thirdly, under joint efforts of teachers and students, students should learn to innovate in PE teaching, boost their autonomous learning ability, transform passive physical exercise thought and transit from "I am asked to take exercise" to "I want to take exercise".

\section{Principles of Sunshine Sports education}

Principle of science and interestingness

Sunshine Sports education deems education as the fundamental principle. Colleges should be people-oriented and stress the education, interestingness and science principle of Sunshine Sports in education process. Based on education development principle and sports activity rules, colleges 
should establish course system by focusing in students' physical and mental development, enrich course contents, teach through lively activities, improve and maintain students' interest in PE course.

Principle of combining traditional PE teaching

Although Sunshine Sports emphasizes a brand-new educational idea, it is also based on traditional $\mathrm{PE}$ teaching. Colleges should standardize college-running behavior, deepen teaching reform mechanism in strict accordance with the norms about PE provided by the Ministry of Education, discover shortcomings in practice, embody teaching quality and deepen agreement with traditional PE teaching through guiding and encouraging all students to participate in Sunshine Sports activity while implementing Sunshine Sports education.

Principle of combining extracurricular PE teaching

Except coordinating with on-campus PE teaching materials, colleges should make sure students stick to physical exercise after class, extend Sunshine Sports education to extracurricular physical exercise and form a mechanism. Sunshine Sports advocates to activity construct the teaching mode dominated by happy mode and free sports, and intensify students' training process after class. For example, extracurricular sports competition, collective field items and extracurricular sports with local national characteristics may be carried out to enrich the contents that students cannot learn in classroom. In extracurricular PE teaching, Sunshine Sports also underlines safety supreme principle and intensifies safety education idea. If necessary, colleges should establish emergency prevention measures and protect life safety of college students ${ }^{[1]}$.

\section{Implementation of Sunshine Sports education in D College}

\section{Survey of students' participation motivation after D College conducts Sunshine Sports education}

D College started to carry out Sunshine Sports education from 2015. Through the survey of students' Sunshine Sports participation motivation, colleges can know students' cognition degree for Sunshine Sports. Meanwhile, the survey also concerns whether students can participate in Sunshine Sports education activity for a long time.

It is found through a series of investigations that, the participation motivation of students in D College presents diversity. Nearly $35.5 \%$ students want to do physical exercise; $21.2 \%$ students consider Sunshine Sports is a way for daily entertainment and emotion adjustment; $16.1 \%$ students want to cultivate lifelong sports habit through Sunshine Sports; 8.3\% students participate in Sunshine Sports out of social contact need; $12.34 \%$ students are for the purpose of the credit; the remaining 6.56\% students want to master sports skills and become a professional athlete. Different students have certain cognitive differences and purposes when selecting participation in Sunshine Sports. If colleges choose Sunshine Sports education, they should intensify cultivation of students' lifelong sports awareness, gradually guide students' participation motivation and make sure they really achieve lifelong sports and lifelong exercise while enriching PE teaching.

Survey of students' participation events after D College conducts Sunshine Sports education

The second survey is based on that which sports events are chosen by students in Sunshine Sports education. In D College, the top 3 events for boys are as follows: basketball (25.0\%), football (10.7\%) and badminton (10.3\%); the top 3 events for girls are as follows: badminton (20.5\%), aerobics (14.4\%) and dance (19.1\%). It thus can be seen that boys and girls differ a lot in sports event selection. The survey reflects humanistic thought in Sunshine Sports education. Course arrangement should be based on students' interest. At present, although some colleges carry out Sunshine Sports education, they fail to deeply analyze students' interest in sports events. Thus, course content setting has certain gap with real conditions, which needs correction urgently. Sunshine Sports can own larger development space only when it better mobilizes students' participation and enthusiasm ${ }^{[2]}$.

\section{Restraining factors of Sunshine Sports education implementation by D College}

Although D College has implemented Sunshine Sports for over one year, the implementation effect is poor. Less than $30 \%$ students really continue to participate in it. Many students give up halfway for various reasons. Through the survey, this paper summarizes main restraining factors of Sunshine Sports education implementation by D College. 


\section{Student level}

\section{Lack of physical exercise awareness}

In the survey, nearly 60\% students cannot understand the connotation of Sunshine Sports education and lack physical exercise awareness. They are unwilling to waste too much time on physical exercise. Due to diversity of current leisure and recreation ways and gradual change of students' thinking awareness, few students are willing to participate in physical exercise, so sports consciousness of students in D College fails to form.

Students' employment pressure is large

At present, as social employment pressure becomes heavier and heavier, college talent competition also becomes increasingly fierce. Like other colleges, the students in D College spend most of their energy in getting various certificates, and they spend most time on examinations. They have no time to take into account of physical exercise. Thus, the implementation situation of Sunshine Sports education is not ideal.

Bad life style

The life style of college students is very irregular, which is also the common problem of Chinese college students. D College is also the case. Many college students have bad living habits, such as sleeping late, waking up late, smoking, smoking and irrational diet structure. Such bad habits affect students' Sunshine Sports participation mood, as time passes and also influence the fitness effect of Sunshine Sports education.

\section{College level}

Confused concept

Although Sunshine Sports education has been implemented for nearly one year in D College, many students and even teachers confuse Sunshine Sports education and traditional PE. In D College, many routine PE course is also disguised in the name of Sunshine Sports education. In fact, pertinence, planning and connotation of Sunshine Sports education do not exist. Moreover, D College fails to propose and formulate long-term detailed implementation plan for Sunshine Sports education and fails to profoundly cognize integration of National Students' Health Standards. Hence, Sunshine Sports education implementation is still in the vague state in D College.

Insufficient hardware equipment

D College needs to improve hardware equipment. For example, the number of outdoor basketball courts and tennis courts is relatively large, but the quantity of indoor sports halls is small. These result in server shortage of sports field. These hardware factors give rise to certain negative effects on Sunshine Sports, strictly restrict flexibility of Sunshine Sports education in extracurricular PE teaching and reduce extracurricular athletic contest implementation degree and students' participation enthusiasm.

\section{Sunshine Sports education reform measures of D College}

Based on the above problems and surveys, this paper discusses Sunshine Sports education reform measures of D College from three aspects: cognition, guarantee measures and reform direction.

\section{To improve cognition and intensify campus atmosphere}

D College is deficient in Sunshine Sports education. Firstly, D College should intensify advertising and communicate health concept of Sunshine Sports education through multiple channels such as broadcasting station, bulletin board, slogan, network and school magazine. The college should utilize current campus internet resource to establish "Sunshine Sports Education" website, carry out online education course, health knowledge lecture and academic knowledge seminar as well as other rich and interesting Sunshine Sports education activities. Meanwhile, the college should actively infuse such ideas to students as "health first, reaching the standard, striving for excellence, body building and taking exercise for 1h every day", overall popularize and enrich students' PE view and health view as well as create favorable public opinion environment of "Sunshine Sports" on campus.

On the other hand, D College may carry out "Sunshine Sports Month" in spring and autumn annually, advertise the superiority of Sunshine Sports to both students and teachers intensively for 
one month, and cater to students' interest to implement sports activities such as Carnival, football cup, and sports dancing competition to activate Sunshine Sports education atmosphere.

\section{To enhance guarantee measures of Sunshine Sports education}

The government and local enterprises should give D College certain financial support to smoothly carry out Sunshine Sports education. In this regard, D College also applies for establishing fundraising channel and hopes to establish Sunshine Sports education fund for campus PE. Besides, D College should construct sound fund guarantee mechanism based on Sunshine Sports education, improve treatment of PE teachers, regularly organize teachers for skill learning and training, boost their knowledge theory and technical level and enhance teaching team building.

Furthermore, D College also utilizes the fund to intensify sports hardware infrastructure construction and build multiple sports venues. The spots events students are most interested in are selected by voting survey. Hardware facilities are further arranged and planned, and equipment construction is transformed to furthest utilize the equipment and give play to their functions. Besides, "Sunshine Sports Exercise" plan is set to guide students to independently participate in physical exercise regularly.

\section{To reform and enrich PE course type}

In accordance with Physical Education Curriculum Guiding Outline for Common Institutes of Higher Learning in China issued by the state, D College has carried out targeted reform of campus PE course based on Sunshine Sports education principles. For example, two-year PE course is set for freshmen and sophomores, and the course items involve nearly 15 sports events for students. To intensify Sunshine Sports education awareness, D College transforms original general PE course to optimal course, club teaching, specific technology promotion course and health care course etc. The college suggests students choose general required course in the freshman year, choose optimal course in the sophomore year according to their needs. In the junior year and the senior year, credit-based optimal course, health care course and club teaching course are the main teaching modes. Such course arrangement is very beneficial to fusion of traditional PE course and the concept of Sunshine Sports. The general courses can make students contact more sports events, and know their basic theories and skills. The optimal course stresses training and improvement of students' special skills and abilities, and makes students master sports events for lifelong exercise. Such PE fusion makes students more willing to take part in Sunshine Sports education ${ }^{[3]}$.

\section{Conclusion}

Sunshine Sports education breaks through and optimizes traditional college education. Its teaching idea is more novel; its teaching scope is wider; its teaching thinking is more flexible; its teaching mode is more scientific and basically meets students' requirement, i.e. desire to seek interest in teaching process and learn practical skills. Therefore, except D College, all colleges in China should introduce the concept of Sunshine Sports education in campus, achieve integration of it and traditional education, let college PE own broader development space and achieve the objective of rejuvenating the state and people by PE.

\section{References}

[1] Zhao Qiang, Yao Xuxia, Analysis of Sunshine Sports Development in Common Colleges. Sports Culture Guide, 2010(9):98-100.

[2] Tang Yanjie, Study on Several Problems and Countermeasures of Sunshine Sports Implementation in Common Colleges. Hunan Normal University, 2009.17-21.

[3] Nan Jiangping, Current Situation and Countermeasures off Sunshine Sports Implementation in Common Colleges of Shandong Province. Qufu Normal University, 2011.21-30. 